\title{
Implementation of Accelerometer Sensor Module and Fall Detection Monitoring System based on Wireless Sensor Network
}

\author{
Youngbum Lee and Myoungho Lee \\ Yonsei University, Department of Electrical and Electronic Engineering \\ Republic of Korea
}

\section{Introduction}

ADL means 'Activity of Daily Living' and literally the activity from everyday living. In the early days, the activity measurement system using accelerometer measures in one direction at one part. This method has an advantage that easy and quantitative measurement is possible using one sensor. But that is so simple method that precise activity assessment for various posture classifications in daily living is impossible [2]. For the study about the correlation between the human's movement and energy consumption, the method that measures 3 direction activity data using 3-axis accelerometer sensor is used. This method is better than using many sensors, but the classification for various human's movement is still impossible [5]. In this study, using accelerometer sensor module, we develop the algorithm that classify the wearer's posture and activity. And we implement the monitoring system based on wireless sensor network. For the performance assessment of developed accelerometer module, algorithm and monitoring system, the experiment for 30 subjects is executed.

This research implements wireless accelerometer sensor module and algorithm to determine wearer's posture, activity and fall. Wireless accelerometer sensor module uses ADXL202, 2axis accelerometer sensor (Analog Device). And using wireless RF module, this module measures accelerometer signal and shows the signal at 'Acceloger' viewer program in PC. $\mathrm{ADL}$ algorithm determines posture, activity and fall that activity is determined by AC component of accelerometer signal and posture is determined by DC component of accelerometer signal. Those activity and posture include standing, sitting, lying, walking, running, etc. By the experiment for 30 subjects, the performance of implemented algorithm was assessed, and detection rate for postures, motions and subjects was calculated. Lastly, using wireless sensor network in experimental space, subject's postures, motions and fall monitoring system was implemented. By the simulation experiment for 30 subjects, 4 kinds of activity, 3 times, fall detection rate was calculated. In conclusion, this system can be application to patients and elders for activity monitoring and fall detection and also sports athletes' exercise measurement and pattern analysis. And it can be expected to common person's exercise training and just plaything for entertainment. 


\section{Wireless Accelerometer Sensor Module Design and Implementation}

In this part, we describe the design and implementation of wireless accelerometer sensor module. The system consists of wireless accelerometer sensor module and base station module. In case of wireless accelerometer sensor module, that consists of accelerometer sensor part, MCU (Micro Controller Unit) part and RF part. In case of base station module, that consists of wireless receiver part and USB interface part. Lastly, we describe the monitoring software in PC.
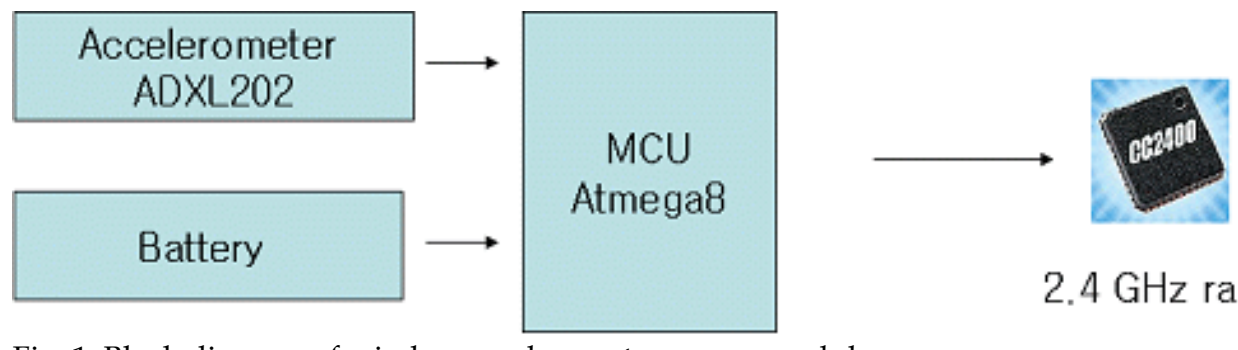

$2.4 \mathrm{GHz}$ radio

Fig. 1. Block diagram of wireless accelerometer sensor module

\subsection{Accelerometer sensor part}

We use ADXL 202 (Analog Device, USA), 2-axis accelerometer sensor that measures +/-2g acceleration and the output is PWM type digital signal. The module receive this signal by interrupt and using timer, the pulse width is calculated and sent to receiver by wireless. The receiver sends this data to USB driver and the 'Acceloger' viewer program collects this data and show the graph in display.

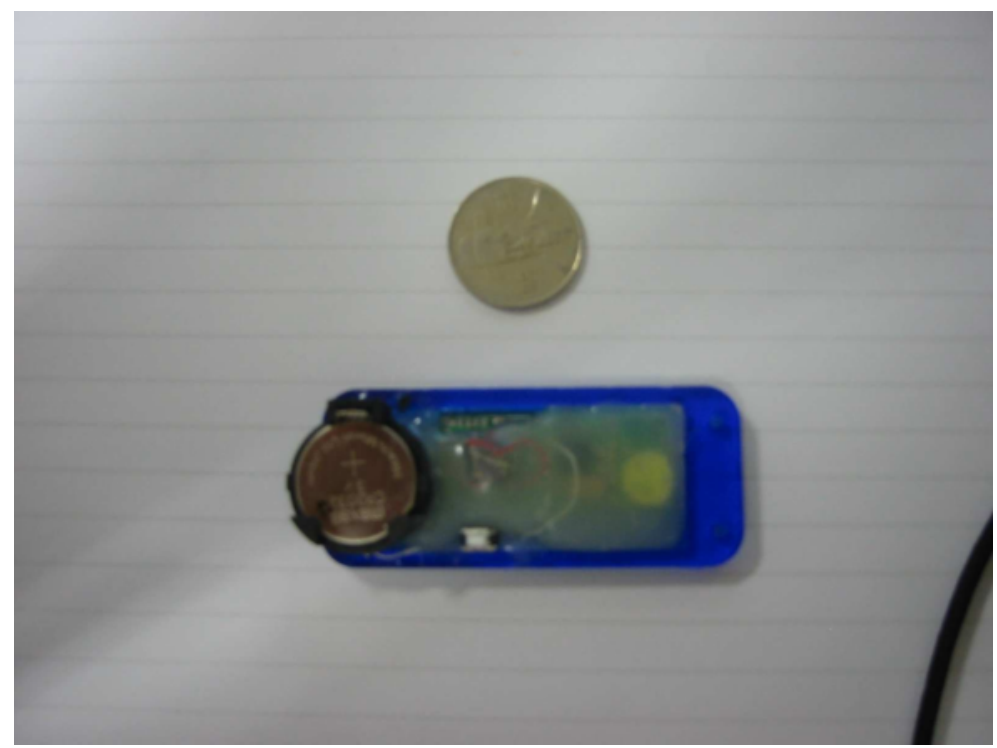

Fig. 2. The size comparison of wireless accelerometer sensor module 


\subsection{MCU module}

We use ATmega8 (ATMEL, USA), and SPI port is used for firmware writing and SD card interface. Using embedded ADC, MCU read the output of accelerometer sensor. MCU give the serial clock at wireless module and read the packet data from wireless module. ATmega series have advantage to develop firmware more easily using efficient GCC and Tool-chain.

\subsection{RF wireless module}

$2.4 \mathrm{GHz}$ wireless radio chip has advantage of its chip size and transmission speed. So, it is good for embedded application, but its directivity is high, so if there are some obstacles, the communication doesn't work well. This problem can be solved using wireless sensor network. We use wireless radio chip nRF2401 (nVLSI, Norway). This chip is connected to MCU by 8 pin connector. This chip has double independent transceiver, but we use only one transceiver. Transceiver uses 76 channels from $2.4-2.5 \mathrm{GHz}$ frequency band. We set up that the channel can be used by any users. The communication protocol in link layer use Shock Burst embedded in nRF2401 chip. In this mode, 32 byte data can be transmitted with 256 Kbps or $1 \mathrm{Mbps}$ speed. One wireless data packet is 256 bit (32 byte) that consists of 40 bit receiver address, 40 bit sender address, 20 byte data and 2 byte CRC field. Transceiver treats transmission to receiver and CRC check task. Antenna is located in PCB board as pattern type.

\subsection{Wireless receiver}

Wireless receiver is small dongle type device connected to USB port in PC to deliver the acceleration signal to PC. Wireless receiver has also ATmega microcontroller and nRF2401 radio chip. ATmega microcontroller uses firmware to implement USB packet processor for USB Slave. We develop this using AVR-GCC in window's virtual Linux environment (CygWin). And this has wireless chip control function such as wireless packet validation, wireless packet rearrangement and wireless packet error correction. In case of USB Slave, we implement firmware for relatively simple low speed $(1.1 \mathrm{Mbps})$ control transfer. This process is described below.

- When inserted at USB port that is worked as low speed USB mode delivers various descriptors to host and finish the setup process.

- In host's control packet's user function definition, lamp blinking, RF packet read and RF packet write function's service routine is embedded and these 3 routines can be executed using control packet's function number.

\subsection{Acceleration signal viewer program}

Figure 3 shows the signal when we take the wireless acceleration module in hand and shake. Upper graph is $\mathrm{X}$ axis information, lower graph is $\mathrm{Y}$ axis information. When the 'Cont' checkbox is pushed, the program received the data continuously. 'LedOn' and 'LedOff' buttons show the receiver's status and used when the receiver's LED is blinking. 'Open' button is used when connecting to device driver. 'GetIO', 'GetRF' and 'RXMODE' buttons are for wireless communication debugging and change the mode of wirless receiver's IO register dump, wireless packet data dump and receiver's wireless transceiver to receiving mode forcibly. Data transmission speed is controlled by changing the firmware. 


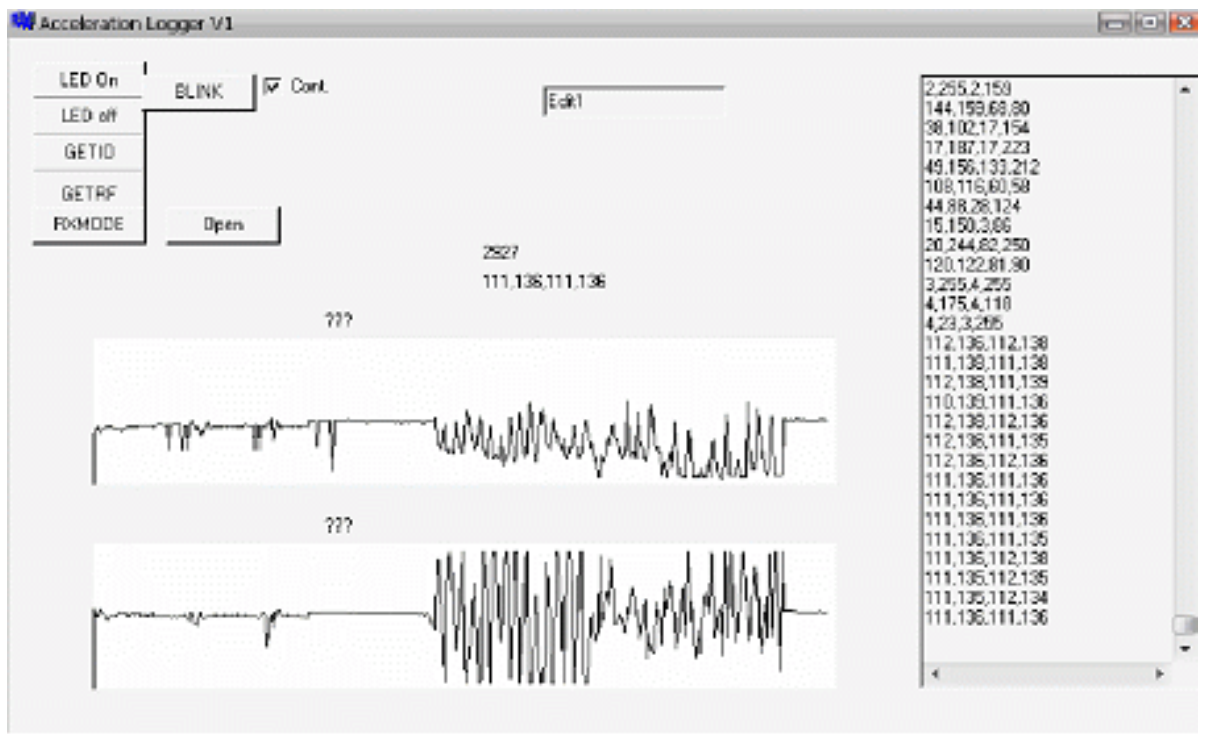

Fig. 3. 'Acceloger' viewer program

\section{Implementation of Fall detection monitoring system based on Wireless Sensor Network}

Wireless sensor network is currently almost standardized by 'Zigbee', but when there are specific purpose and limited space, it is better to have optimized wireless communication stack in wireless sensor network. In this case, there are max 8 relay-nodes in one basestation. And each relay-node can have max 32 mobile-nodes or fixed-nodes in topology. Every relay-node, fixed-node and mobile-node can be freely configured as master or slave. Fixed-node and mobile-node are not in specific relay-node but connected to voluntary one or many relay-nodes.

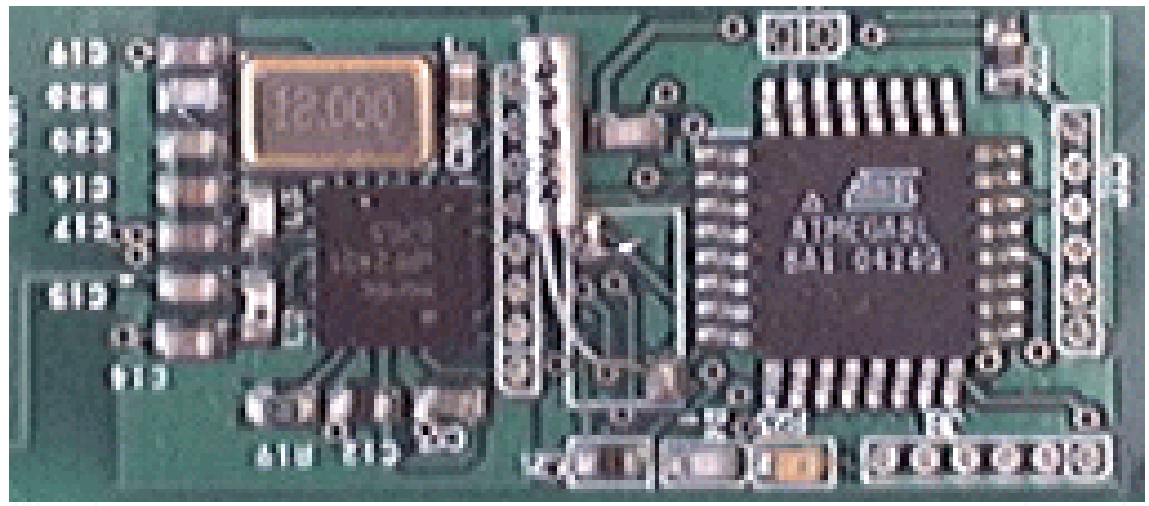

Fig. 4. Developed wireless sensor network RF module 


\subsection{Wireless sensor network design}

First, relay-node has a function to repeat retransmitting the received wireless packet infinitely. But when retransmitting, relay-node turn on ID bit in packet's specific item and increase relay-node's counter number by 1 . This function definition is the minimum condition for ad-hoc network and self organizing network. Fixed-node makes and transmits the wireless packet by constant time interval or specific event. The packet from fixed-node has logical serial number, relay-node's ID item, relay-node's counter number and sensor value. Mobile-node has mobility and other character is same as fixed-node. Wireless acceleration sensor can be modeled as mobile-node because that is taken by mobile object. The relay-node's situation is very non-deterministic that is typical feature of wireless sensor network. Relay-node is installed in fixed location and each relay-node's location must be considered carefully. Relay-node is basically located within other relay node's visibility range because $2.4 \mathrm{GHz}$ radio wave has strong directivity. By relay-node's antenna sensitivity and transmission power, the distance between relay-node can be different but typically, when $0 \mathrm{dBm}(1 \mathrm{~mW}), 10 \mathrm{~m}$ is the basis. This system uses $1 \mathrm{dBm}$ output. The topology can be serial, star shape, circle or informal, but each relay-node must link to at least one relay-node or base-station.

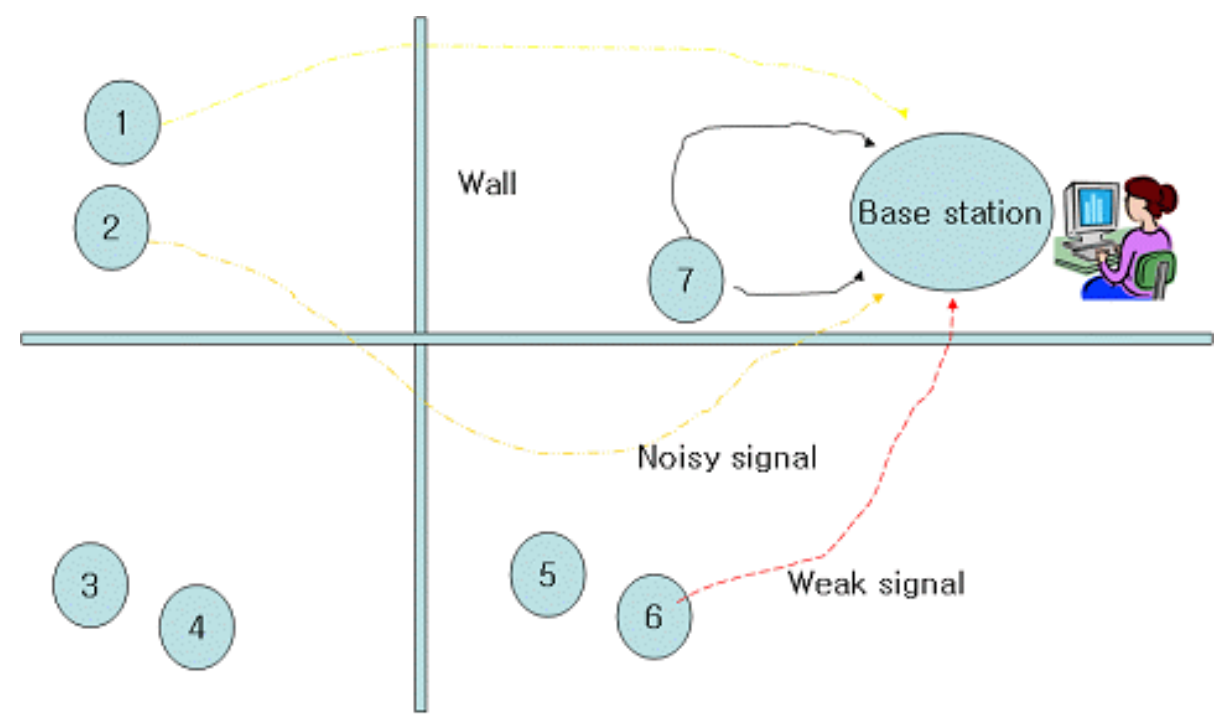

Fig. 5. Simple wireless sensor network without repeater 


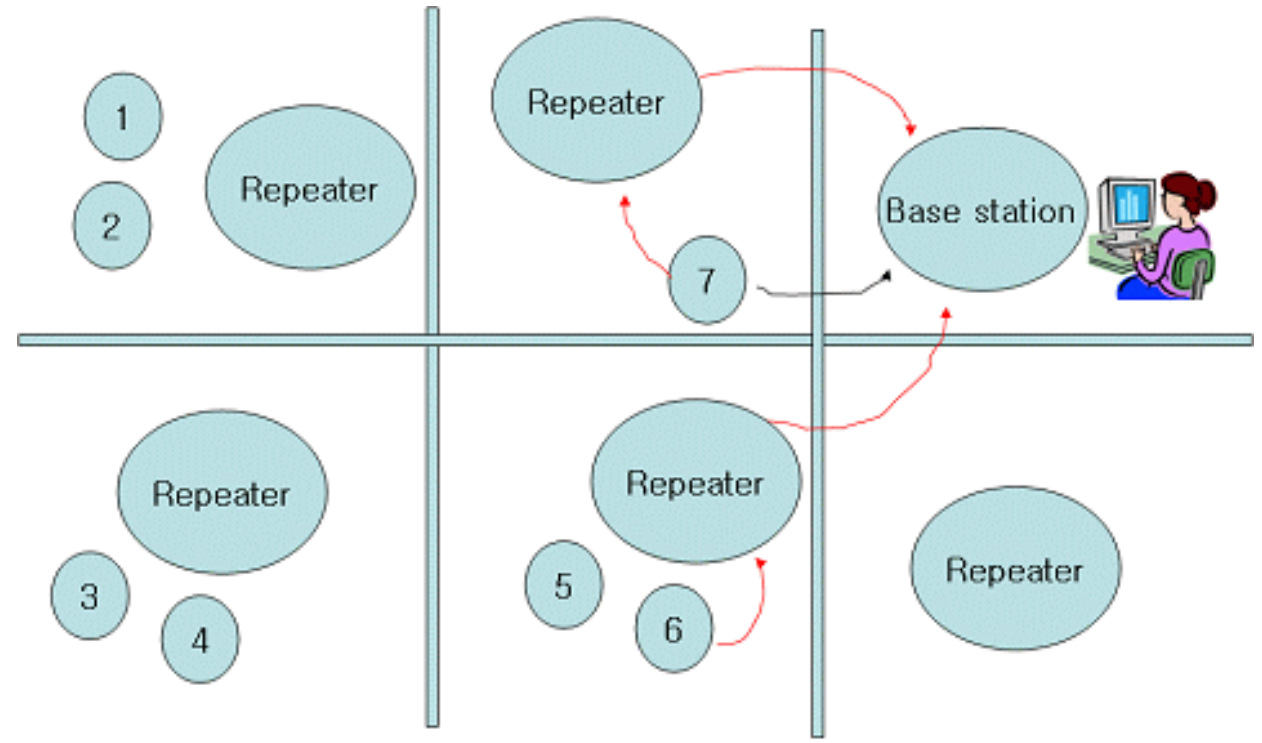

Fig. 6. The example of wireless sensor network construction using repeater

In above figure, the signal from wireless acceleration sensor module can go directly to basestation or go through relay-node. Relay-node inserts the information in wireless packet. Using this method, we install the relay-node in each room and make wireless sensor network. When the RF wave has a problem to go directly to base-station, it goes through relay-node. In this point, wireless sensor network algorithm must solve the complex problem that is infinitely repeatable stray packet detection between relay-node, unnecessary retransmission between relay-node, optimal shortest path finding problem between basestation and specific relay-node in very complex topology. To solve these 3 problems, the system typically becomes very complex. In this system, the design purpose is minimum power consumption, minimum hardware implementation, and optimized algorithm for small sensor network in limited space. So, we don't consider optimal path finding problem and redundant retransmission problem but detect and remove the critical stray packet for network management. Relay-node changes the counter value and prevents the transmitted packet from receiving. In this case, this algorithm doesn't relay any more that stop infinite repetitions.

\subsection{Monitoring system development}

Figure 7 shows implemented monitoring program based on wireless sensor network. The program reads the plain figure of rooms and we can configure the location of relay-node using mouse pointer. (point A, B, C, D in figure) each wireless station is appeared around relay-node by number character. 


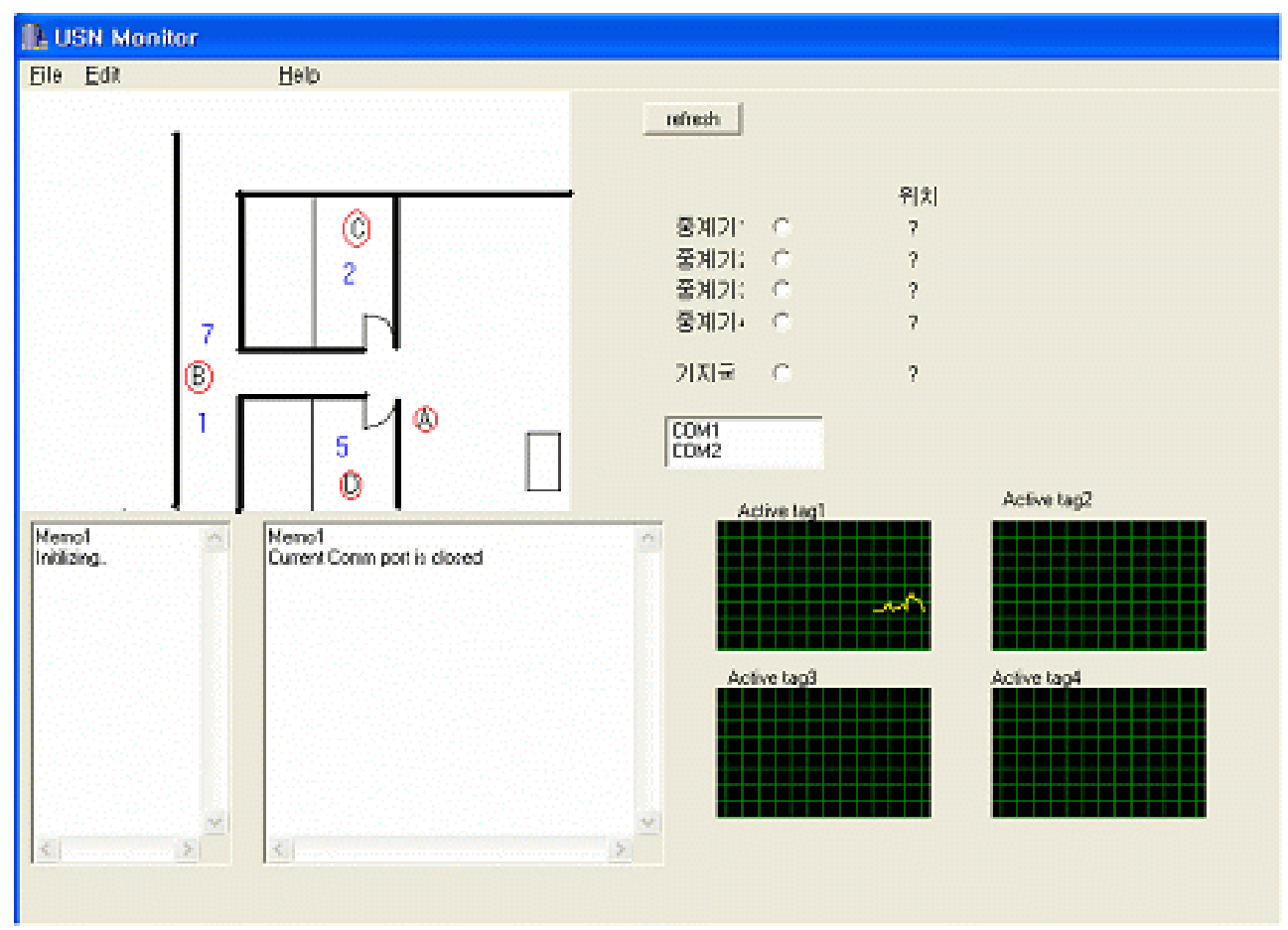

Fig. 7. Implemented monitoring system based on wireless sensor network

\section{Experiment and Discussion}

The implemented monitoring system based on wireless sensor network is installed in experimental space and as the result of the experiment; we obtain the posture, activity and fall detection rate for subjects. Specially, we assume this system can be application for patient's and elderly fall detection in sanatorium and hospital, and execute the simulation. In this experiment, we classify the fall into forward fall, backward fall, side fall and just sitting and standing. And the detected fall is marked as 'Success' and the undetected fall is 'Fail'. In case of just sitting and standing, when the fall is not detected, that means 'Success'. For 30 subjects, we repeat the above 4 kinds of activity by 3 times in experimental space. For all 360 fall simulation tries, the 337 falls are detected and 23 falls are not detected. The fall detection rate is $93.2 \%$.

\begin{tabular}{lllll}
\hline $\begin{array}{l}\text { Gender, } \\
\text { Number }\end{array}$ & Item & Avg \pm SD & Min & Max \\
\hline Male, 20 & Age & $26.4 \pm 3.67$ & 20 & 32 \\
\cline { 2 - 5 } & Height & $175.8 \pm 4.20$ & 168 & 185 \\
\cline { 2 - 5 } & Weight & $70.3 \pm 6.64$ & 58.1 & 85 \\
\hline
\end{tabular}




\begin{tabular}{llllll}
\hline \multirow{2}{*}{$\begin{array}{l}\text { Female, } \\
10\end{array}$} & Age & $28 \pm 3.26$ & 21 & 31 \\
\cline { 2 - 5 } & & Height & $161.1 \pm 5.30$ & 152 & 171 \\
\cline { 2 - 5 } & Weight & $55.6 \pm 6.72$ & 46.2 & 67.4 \\
\cline { 2 - 5 } & Total 30 & Age & $26.9 \pm 3.61$ & 20 & 32 \\
\cline { 2 - 5 } & & & & 152 & 185 \\
\cline { 2 - 5 } & Height & $170.9 \pm 8.31$ & 46.2 & 85 \\
\cline { 2 - 5 } & & Weight & $65.4 \pm 9.62$ & 46
\end{tabular}

Table 1. General data of 30 subjects

\begin{tabular}{ccccccccc}
\hline Tries & \multicolumn{7}{c}{ Fall Detection } \\
\cline { 2 - 9 } & Forward & \multicolumn{1}{c}{ Backward } & \multicolumn{2}{c}{ Side } & \multicolumn{2}{c}{ Sit and Stand } \\
\cline { 2 - 9 } & S & F & S & F & S & F & S & F \\
\hline 1 & 28 & 2 & 27 & 3 & 29 & 1 & 30 & 0 \\
\hline 2 & 28 & 2 & 28 & 2 & 27 & 3 & 29 & 1 \\
\hline 3 & 27 & 3 & 27 & 3 & 28 & 2 & 29 & 1 \\
\hline Total & 83 & 7 & 82 & 8 & 84 & 6 & 88 & 2 \\
\cline { 2 - 8 } & & & &
\end{tabular}

Success : 337 Fail : 23

Table 2. Fall detection rate using wireless sensor network monitoring system

\section{Conclusion}

In this study, using acceleration sensor, we implement wireless acceleration sensor module and algorithm to detect wearer's posture, activity and fall. To assess the performance of algorithm, in specific space, we develop wearer's posture, activity and fall detection monitoring system, and for 30 subjects, the fall simulation experiment is executed for 4 kinds of activity, 3 times and calculate fall detection rate. The result is 337 times detection success and 23 times fail among 360 tries. So, fall detection rate is $93.2 \%$. The developed system can be used for patient or the senior people's activity monitoring and fall detection, also, sports athlete's activity measurement and pattern analysis, normal people's exercise learning and just plaything.

\section{References}

Henry J. Montoye, Han C. G. Kemper, Wim H. M. Saris, Richard A. Washburn, "Measuring physical activity and energy expenditure", Human Kinetics, pp.72-96, 1996.

Kim L. Coleman, Douglas G. Smith, David A. Boone, Aaron W. Joseph, Michael A. del Aguila, "Step activity monitor: long-term, continuous recording of ambulatory function", Journal of Rehabilitation Research and Development, Vol.36, NO.1, 1999.

F. Foerster, M. Smeja, J. Fahrenberg, "Detection of posture and motion by accelerometry: a validation study in ambulatory monitoring", Computers in Human Behavior, Vol.15, pp.571-583, 1999. 
H. G. van Steenis, J. H. M. Tulen, "The effects of physical activities on cardivascular variability in ambulatory situations", Proceedings-19th International ConferenceIEEE/EMBS, pp.105-108, 1997.

Carlijn V.C. Bouten, Karel T. M. Koekkoek, Maarten Verduin, Rens Kodde, Jan D. Janssen, "A triaxial accelerometer and portable data processing unit for the assessment of daily physical activity", IEEE Transactions on Biomedical Engineering, Vol.44, pp.136-147, 1997.

K. Aminian, Ph. Robert, E. E. Buchser, B. Rutschmann, D. Hayoz, M. Depairon, "Physical activity monitoring based on accelerometry: validation and comparison with video observation", Medical \& Biological Engineering \& Computing, Vol.37, pp.304-308, 1999.

B. Najafi, K. Aminian, F. Loew, Y. Blanc, "An ambulatory system for physical activity monitoring in elderly", IEEE-EMBS Special Topic Conference on Microtechnologies in Medicine \& Biology, pp.562-566, 2000.

S. H. Lee, H. D. Park, H. R. Yoon, K. J. Lee, "Design of a Portable Activity Monitoring System", The Korean Institute of Electrical Engineer, Vol.51, pp.32-38, 2002

Bijan Najafi, "Ambulatory System for Human Motion Analysis Using a Kinematic Sensor: Monitoring of Daily Physical Activity in the Elderly", IEEE Trans. on biomedical Engineering, Vol. 50, No.6, June 2003

G.Williams, "A Smart Fall \& Activity Monitor for Telecare Application", Proceeding of the 20th Annual International Conference of the IEEE Engineering $\mathrm{n}$ Medicine and Biology Society, 1998

J.Y.Hwang, "Development of Novel Algorithm and Real-time Monitoring Ambulatory System Using Bluetooth Module for Fall Detection in the Elderly", Proceedings of the 26th Annual International Conference of the IEEE EMBS San Francisco, CA, USA, September 1-5, 2004 
www.intechopen.com 


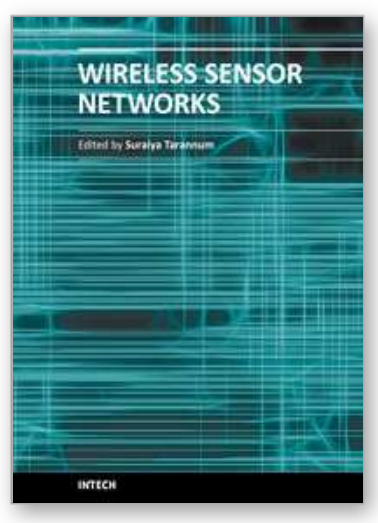

\section{Wireless Sensor Networks \\ Edited by}

ISBN 978-953-307-325-5

Hard cover, 342 pages

Publisher InTech

Published online 29, June, 2011

Published in print edition June, 2011

\section{How to reference}

In order to correctly reference this scholarly work, feel free to copy and paste the following:

Youngbum Lee and Myoungho Lee (2011). Implementation of Accelerometer Sensor Module and Fall Detection Monitoring System based on Wireless Sensor Network, Wireless Sensor Networks, (Ed.), ISBN: 978953-307-325-5, InTech, Available from: http://www.intechopen.com/books/wireless-sensornetworks/implementation-of-accelerometer-sensor-module-and-fall-detection-monitoring-system-based-onwireless

\section{INTECH}

open science | open minds

\section{InTech Europe}

University Campus STeP Ri

Slavka Krautzeka 83/A

51000 Rijeka, Croatia

Phone: +385 (51) 770447

Fax: +385 (51) 686166

www.intechopen.com

\section{InTech China}

Unit 405, Office Block, Hotel Equatorial Shanghai

No.65, Yan An Road (West), Shanghai, 200040, China

中国上海市延安西路65号上海国际贵都大饭店办公楼405单元

Phone: +86-21-62489820

Fax: +86-21-62489821 
(C) 2011 The Author(s). Licensee IntechOpen. This chapter is distributed under the terms of the Creative Commons Attribution-NonCommercialShareAlike-3.0 License, which permits use, distribution and reproduction for non-commercial purposes, provided the original is properly cited and derivative works building on this content are distributed under the same license. 